\title{
Ammonium nitrate explosion at the main port in Beirut (Lebanon) and air pollution: an analysis of the spatiotemporal distribution of nitrogen dioxide
}

\author{
Tarig Ali ${ }^{1} \cdot$ Mohamed Abouleish $^{2} \cdot$ Rahul Gawai $^{3} \cdot$ Nasser Hamdan $^{4} \cdot$ Ahmed Elaksher $^{5}$ (1)
}

Received: 3 May 2021 / Accepted: 4 February 2022 / Published online: 26 February 2022

(c) Springer Nature Switzerland AG 2022

\begin{abstract}
An explosion of the ammonium nitrate (AN) stored at Beirut Port devastated the city on Tuesday 4 August 2020. Such an explosion produces pollutants such as nitrogen oxides $\left(\mathrm{NO}_{x}\right)$. The most common $\mathrm{NO}_{x}$ is nitrogen dioxide $\left(\mathrm{NO}_{2}\right)$, which is present in the atmosphere due to natural and anthropogenic processes. The presence of $\mathrm{NO}_{2}$ is used as indicator of air pollution. However, the specific contribution of $\mathrm{NO}_{2}$ to air quality is uncertain due to the presence of other constituents, especially particulate matter (PM10). Research has shown that extended exposure to $\mathrm{NO}_{2}$ may result in serious health effects. This study investigated the impact of the explosion on $\mathrm{NO}_{2}$ levels in the atmosphere above Beirut and the surrounding area. $\mathrm{NO}_{2}$ data from the Sentinel-5P program were used to map the levels of $\mathrm{NO}_{2}$. Furthermore, ground-monitoring data were used to assess the levels of PM10 and ozone $\left(\mathrm{O}_{3}\right)$ due to the evident association between these constituents and $\mathrm{NO}_{2}$. Results showed that $\mathrm{NO}_{2}$ levels were higher than before the blast. However, 7 days after the explosion, $\mathrm{NO}_{2}$ levels had returned to normal, while the levels of PM10 and $\mathrm{O}_{3}$ remained normal following the explosion. However, a slight increase in the daily average atmospheric pressure was noticed after the explosion, which was attributed to the decomposition of ammonium nitrate.
\end{abstract}

Keywords Beirut explosion $\cdot$ Ammonium nitrate $\cdot$ Air pollution $\cdot$ Nitrogen dioxide $\cdot$ Sentinel-5P data

\section{Introduction}

Amid the coronavirus pandemic around the world and the increasing number of deaths caused by it, an explosion occurred at the main port of Beirut, Lebanon, that added more casualties and suffering to the country and its people.

Responsible Editor: Anthony Lehmann, Chief Editor.

Ahmed Elaksher

elaksher@nmsu.edu

1 Department of Civil Engineering, American University of Sharjah, Sharjah, United Arab Emirates

2 Department Biology, Chemistry and Environmental Sciences, American University of Sharjah, Sharjah, United Arab Emirates

3 GIS and Mapping Lab, American University of Sharjah, Sharjah, United Arab Emirates

4 Department of Physics, American University of Sharjah, Sharjah, United Arab Emirates

5 College of Engineering, New Mexico State University, Las Cruces, NM, USA
On 4 August 2020, about 2700 tons of ammonium nitrate (AN) that were stored at the port exploded, causing mass destruction that extended $20 \mathrm{~km}$ from the port (Silva 2020; OCHA 2020). The explosion affected the surrounding residential and business communities and caused about $150+$ deaths, 5000+ injuries, and left 300,000+ people homeless (OCHA 2020). In addition to the structural damage that the city of Beirut endured, an explosion of such magnitude involving the combustion of AN releases air pollutants, including particulate matter (PM), that cause a deterioration in both outdoor and indoor air quality. The level of health effects varies according to the amount of pollutants that people are exposed to and the protective measures they adopt, which largely depend on their perception and awareness of the situation (Abouleish 2020). Although AN is stable at ambient pressure and temperature, does not burn, and is used as a fertilizer, under the right conditions it can act as an explosive (USEPA 2015; Sinditskii et al. 2005). As a result, the explosion of AN at the Port of Beirut led to the release of toxic gases such as ammonia and nitrogen oxides, as well as other pollutants, depending on the other chemicals present (USEPA 2015). 
The most hazardous oxides of nitrogen are nitrogen dioxide $\left(\mathrm{NO}_{2}\right)$ and nitric oxide (NO) (NLM 2020). Although these nitrogen oxides are present naturally in the environment, anthropogenic sources such as the explosion at the main port of Beirut can increase their levels in the environment and cause health and environmental problems. Shortterm exposure to nitrogen oxides can cause eye and skin irritation/burns, respiratory problems, coughing and choking, headache, nausea, and abdominal pain (NLM 2020). Research has shown that exposure to high levels of $\mathrm{NO}_{2}$ can have a severe impact on public health. For example, Saeha et al. (Shin et al. 2020) uncovered a correlation between exposure to $\mathrm{NO}_{2}$ and high blood pressure, Gan et al. (2012) reported a connection to cardiovascular diseases, and Abbey et al. (1993) presented evidence relating such exposure to obstructive pulmonary disease. Furthermore, such exposure may adversely affect lung function in children (Avol et al. 2001) and middle-aged adults (Bowatte et al. 2017). Therefore, we studied the initial impact of the explosion at the main port of Beirut on $\mathrm{NO}_{2}$ levels in the atmosphere. We used Sentinel-5P program data to map the spatiotemporal levels of tropospheric $\mathrm{NO}_{2}$ over a period of 8 days from the event. In addition, ground-monitoring data were used to assess the levels of particulate matter (PM10) and ozone due to the evident association between these constituents and $\mathrm{NO}_{2}$.

\section{Experimental procedures}

Daily levels of atmospheric $\mathrm{NO}_{2}$ were obtained from the Sentinel Hub, which provides this product along with other atmospheric constituents acquired by the European Commission's Sentinel-5P sensor, which has a spatial resolution of $5.5 \mathrm{~km}$. Sentinel-5P is part of the European Commission's Earth Observation Program, but this mission is specifically designed for air monitoring purposes (Ogen 2020; Veefkind et al. 2012). Sentinel-5P operates in seven spectral bands: 270-300 nm, 300-370 nm, 370-500 nm, 685-710 nm, 745-773 nm, 1590-1675 nm, and 2305-2385 nm. Table 1 below shows the Sentinel-5 $\mathrm{P} \mathrm{NO}_{2}$ image acquisition times. The image from 4 August 2020 (the day of the explosion) was acquired at $10.48 \mathrm{am}$ (Lebanon time), about $8 \mathrm{~h}$ before the incident (Sentinel Hub; Sinergise Laboratory for Geographical Information Systems, Ltd. 2020).

The location of the explosion site is shown in Fig. 1. Given that there is a relationship between the presence of $\mathrm{NO}_{2}$ in the atmosphere and the PM10 and $\mathrm{O}_{3}$ levels (WHO 2003), it was important to examine the average daily levels of PM10 and $\mathrm{O}_{3}$ before and after the blast (Table 2). Table 2 shows the average daily PM10 and $\mathrm{O}_{3}$ data on 3-11 August for Beirut. The PM10 data was obtained from the PurpleAir Air Quality Database (PurpleAir 2020). The $\mathrm{O}_{3}$ data
Table 1 Sentinel-5 $\mathrm{P} \mathrm{NO}_{2}$ image acquisition times

\begin{tabular}{|c|c|c|c|}
\hline \multirow[t]{2}{*}{ Date } & \multicolumn{3}{|c|}{ Sentinel-5 $\mathrm{P} \mathrm{NO}_{2}$ image acquisition times } \\
\hline & UTC time & Lebanon time & Time with respect to blast \\
\hline 4 Aug 20 & 7:48:25 UTC & $10: 48 \mathrm{am}$ & $8 \mathrm{~h}$ before blast \\
\hline 5 Aug 20 & $7: 28: 25$ UTC & $10: 30 \mathrm{am}$ & $16 \mathrm{~h}$ after blast \\
\hline 6 Aug 20 & 7:08:11 UTC & 10:08 am & $40 \mathrm{~h}$ after blast \\
\hline 7 Aug 20 & 6:53:11 UTC & 09:53 am & $64 \mathrm{~h}$ after blast \\
\hline 8 Aug 20 & 6:33:11 UTC & 09:33 am & $88 \mathrm{~h}$ after blast \\
\hline 9 Aug 20 & 7:53:11 UTC & $10: 53 \mathrm{am}$ & $112 \mathrm{~h}$ after blast \\
\hline 10 Aug 20 & 7:33:11 UTC & $10: 33 \mathrm{am}$ & $136 \mathrm{~h}$ after blast \\
\hline 11 Aug 20 & 7:18:11 UTC & $10: 18 \mathrm{am}$ & $160 \mathrm{~h}$ after blast \\
\hline
\end{tabular}

were obtained from the World Air Quality Index Database (World Air Quality Index 2020) for the Upper Galilee station, which is located $76 \mathrm{~km}$ to the southeast of Beirut, due to the unavailability of these data for the Beirut station. To investigate the effect of the explosion and the surrounding environmental conditions on the dispersion of the pollutants in the atmosphere, the average temperature, pressure, wind speed, and direction were obtained on 3-11 August 2020 (Table 3) from the Meteoblue Weather Platform (MWP; Meteoblue 2020).

\section{Results and discussion}

Figure 2 shows maps of tropospheric $\mathrm{NO}_{2}$ levels from 4 to 11 August 2020. The map in Fig. 2a shows the $\mathrm{NO}_{2}$ levels a few hours before the explosion. The maps in Fig. 2b-g show that $\mathrm{NO}_{2}$ levels in the air increased following the day of the explosion until the morning of 10 August (acquisition: 10.33 am local time). Figure $2 \mathrm{~h}$ shows levels of $\mathrm{NO}_{2}$ that are comparable to those before the explosion (as illustrated in Fig. 2a). For better visualization, Fig. 3a and b show zooms of the $\mathrm{NO}_{2}$ maps presented in Fig. 2. Note that the key in Fig. 3 shows the United States Environmental Protection Agency (USEPA) air quality classification standard for $\mathrm{NO}_{2}$. The USEPA standard uses five classes of air quality: good, moderate, unhealthy for sensitive groups, unhealthy, and very unhealthy (USEPA 2011). There was a small hotspot over Beirut before the blast (Fig. 2a), but we can see that the hotspot spread over most of Lebanon and the region, especially in the west of Syria, on the days following the blast (Fig. 2a-g). Moreover, it is evident that the gas dissipated in all directions, but mainly in the southeastern to southwestern directions. The concentrations of $\mathrm{NO}_{2}$ were mainly high, ranging mostly from unhealthy to moderate per the USEPA standard, over large areas of Beirut and Lebanon and all the way to western Syria from the day of the explosion, with an average $\mathrm{NO}_{2}$ concentration of about $150 \mu \mathrm{mol} / \mathrm{m}^{2}$. Then, on 


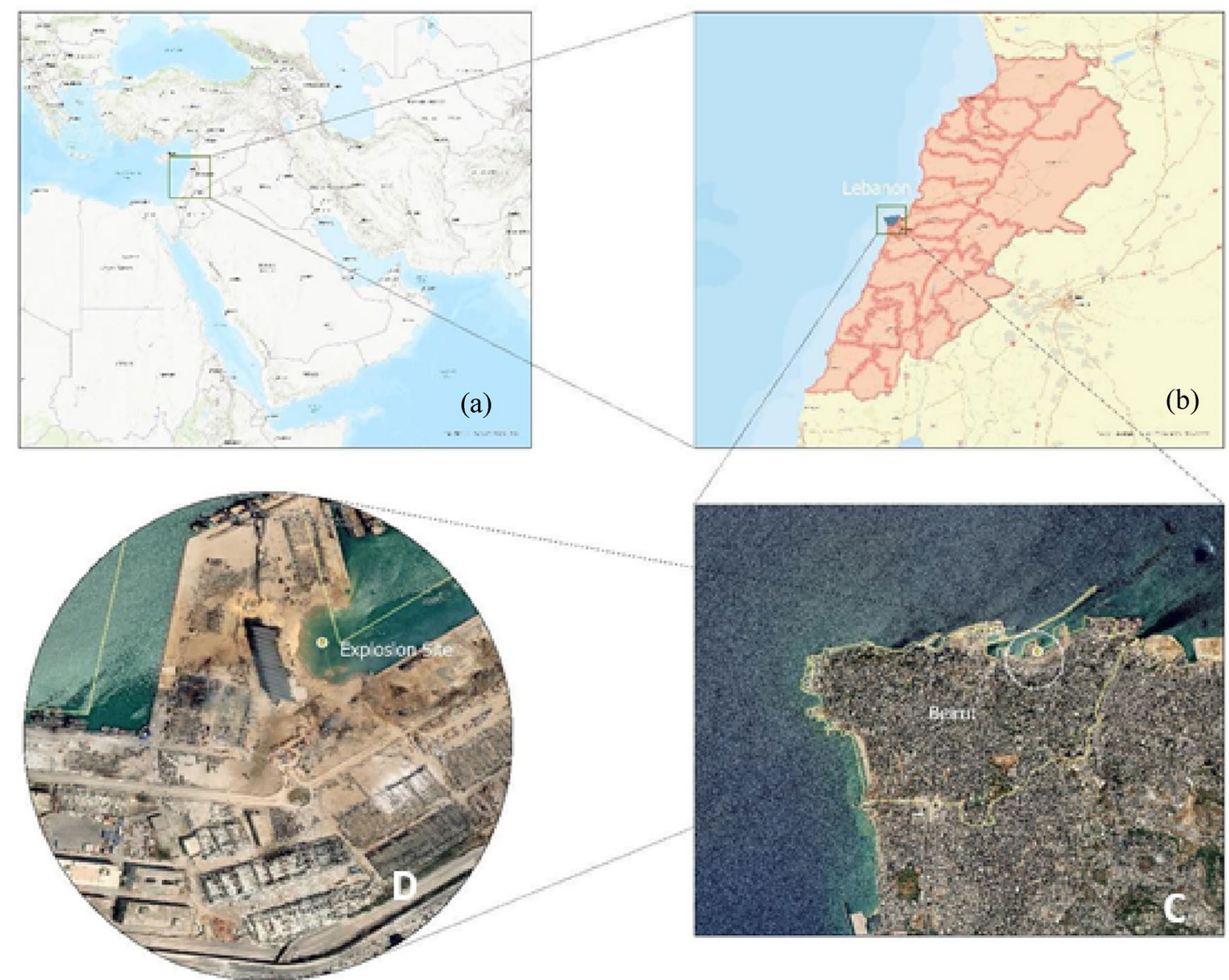

Fig. 1 The explosion site at the main port of Beirut, Lebanon, on 4 August 2020

Table 2 Average levels of PM10 and $\mathrm{O}_{3}$ in the atmosphere in Beirut on 3-11 August 2020

\begin{tabular}{lll}
\hline Date & PM10 $\left(\mu \mathrm{g} / \mathrm{m}^{3}\right)$ & $\mathrm{O}_{3}(\mathrm{ppb})$ \\
\hline 3 Aug 20 & 28.54 & 43 \\
4 Aug 20 & 38.82 & 42 \\
5 Aug 20 & 22.82 & 45 \\
6 Aug 20 & 28.89 & 40 \\
7 Aug 20 & 40.27 & 43 \\
8 Aug 20 & 32.16 & 44 \\
9 Aug 20 & 19.29 & 43 \\
10 Aug 20 & 18.60 & 42 \\
\hline
\end{tabular}

11 August, as shown in Fig. $2 \mathrm{~h}, \mathrm{NO}_{2}$ concentrations returned to the levels seen before the blast.

No change was noticed in the levels of PM10 and $\mathrm{O}_{3}$ in the atmosphere over the studied period. A slight increase in the daily average atmospheric pressure was noticed over the city following the explosion, which can be attributed to the decomposition of ammonium nitrate and the magnitude of the explosion. The maps shown in Figs. 2 and 3 illustrate the spatiotemporal distribution of $\mathrm{NO}_{2}$ over Beirut, Lebanon, and the surrounding region on 4-11 August 2020. Given the depth of the tropospheric layer, we needed to examine the air movement in the vertical direction at the time of the explosion. The latest vertical airflow data was obtained from the NOAA Physical Science Laboratory (PSL) in Boulder, CO, USA (PSL 2020). Figure 4 shows the vertical airflow at $1500 \mathrm{~m}$ above sea level at the explosion site and the surrounding area in July 2020 . The vertical wind, which drives the air column vertically up and down, is represented by the omega equation, which is crucial to weather and storms in meteorology. Positive omega values illustrate downward airflow, while negative values mean upward flow. As shown in Fig. 4, omega was positive at the explosion time, which means that the tropospheric $\mathrm{NO}_{2}$ plume shown in Figs. 2 and 3 was pushed downward-closer to the ground. This would have reduced outdoor and indoor air quality and led to higher exposure to $\mathrm{NO}_{2}$. 
Table 3 Average temperature, pressure, wind speed, and wind direction at the main port of Beirut on 3-11 August 2020 (Meteoblue 2020)

\begin{tabular}{lllll}
\hline Date & Temperature $\left({ }^{\circ} \mathrm{C}\right)$ & $\begin{array}{l}\text { Mean sea-level pres- } \\
\text { sure }(\mathrm{HPa})\end{array}$ & $\begin{array}{l}\text { Wind speed } \\
(\mathrm{km} / \mathrm{h})\end{array}$ & Main wind direction \\
\hline 3 Aug & 24.01 & 1016.342 & 06.43 & S-W/N-W \\
4 Aug & 22.07 & 1011.617 & 10.71 & S-E/S-W \\
5 Aug & 22.78 & 1016.533 & 06.36 & S-W/N-W \\
6 Aug & 22.41 & 1018.779 & 07.83 & N-E/S-E \\
7 Aug & 22.01 & 1019.425 & 03.80 & N-E/S-E \\
8 Aug & 23.01 & 1020.204 & 02.66 & N-W/S-W \\
9 Aug & 24.61 & 1018.985 & 04.43 & S-W \\
10 Aug & 25.83 & 1016.525 & 03.21 & S-W \\
11 Aug & 25.58 & 1013.946 & 06.48 & N-E/S-W \\
\hline
\end{tabular}

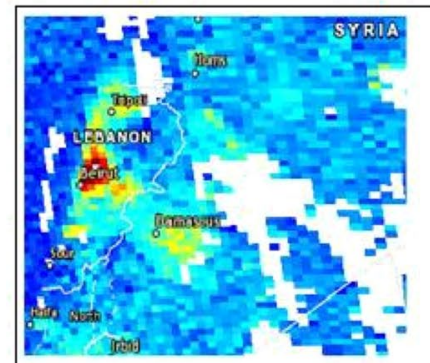

(a) 4 August (before blast)

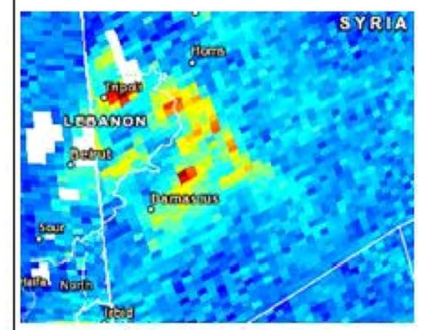

(e) 8 August

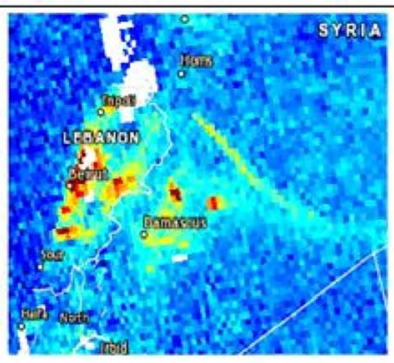

(b) 5 August

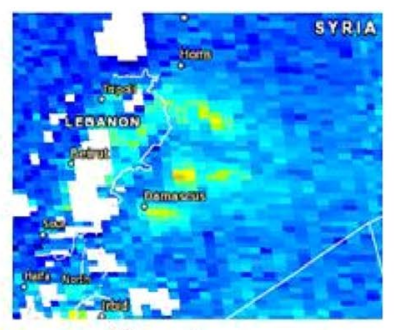

(f) 9 August

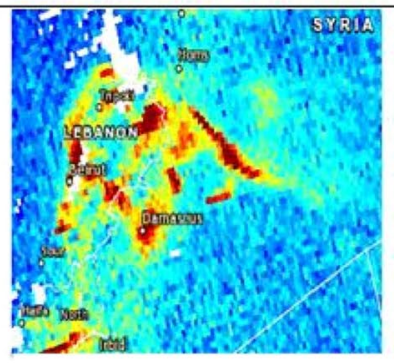

(c) 6 August

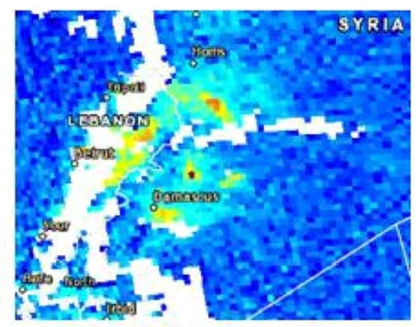

(g) 10 August

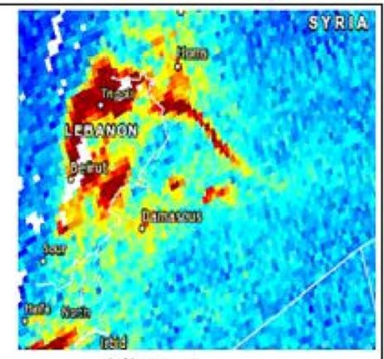

(d) 7 August

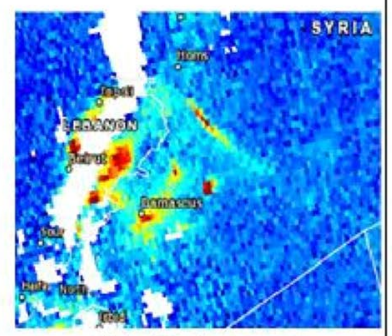

(h) 11 August

Fig. 2 Sentinel-5 $\mathrm{P} \mathrm{NO}_{2}$ maps for 4-11 August 2020 over Beirut (Lebanon) and the surrounding region

\section{Conclusions}

In this study, the levels of tropospheric $\mathrm{NO}_{2}$ above Beirut and the surrounding area, as acquired by the Sentinel-5P satellite, were obtained from the Sentinel Hub and then used to study the effect of the AN explosion in the Port of Beirut on the air quality over Beirut and Lebanon for the eight-day period 4-11 August 2020. The Sentinel$5 \mathrm{P}$ data showed $\mathrm{NO}_{2}$ hotspots over wide areas of Beirut and Lebanon and all the way to Syria. These hotspots increased and spread out after the blast. The average value of the $\mathrm{NO}_{2}$ concentration during this period was about $150 \mu \mathrm{mol} / \mathrm{m}^{2}$, with mainly high concentrations ranging between unhealthy and moderate over most of Beirut from the day of the explosion. These results suggest that high
$\mathrm{NO}_{2}$ concentrations accompanied by a large displaced population (approx. 5000 people) in Beirut presented a major health concern. This situation was aggravated by the downward airflow at the time of the incident. As a result, a high incidence of respiratory problems due to low air quality should be expected. Exposure to such poor air quality may also have caused inflammation in the lungs, which may have undermined the immune response to the already spreading coronavirus (Blomberg et al. 1999). Seven days from the explosion, $\mathrm{NO}_{2}$ levels returned to normal. The levels of PM10 and $\mathrm{O}_{3}$ in the atmosphere remained within the normal range following the explosion. A slight increase in daily average atmospheric pressure was noticed over the city following the explosion, which can be attributed to the decomposition of ammonium nitrate and the magnitude of the explosion. 
Fig. 3 a Sentinel-5P NO 2 maps for 3-6 August 2020 over Lebanon and the surrounding region. b Sentinel-5P NO 2 maps for 7-11 August 2020 over Lebanon and the surrounding region (a)

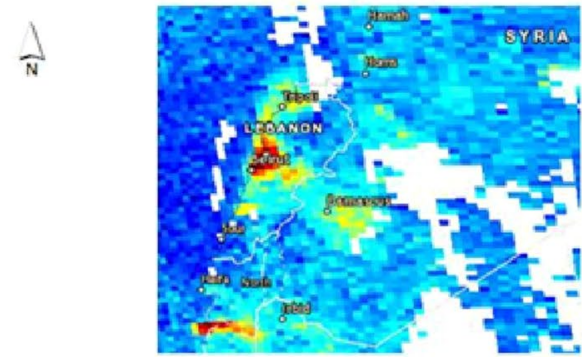

4 August

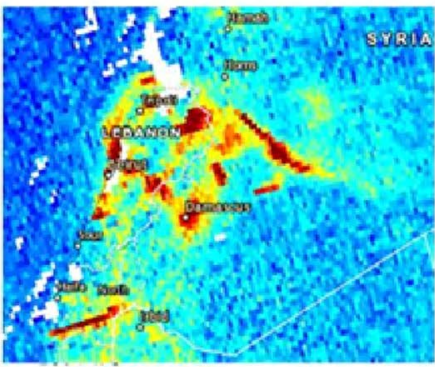

6 August

(b)

$\widehat{N}$

$\mathrm{NO} 2\left(\mu \mathrm{ml} / \mathrm{m}^{2}\right)$

224.0 (Unhealthy)

$0.0(\mathrm{G} \infty \mathrm{d})$

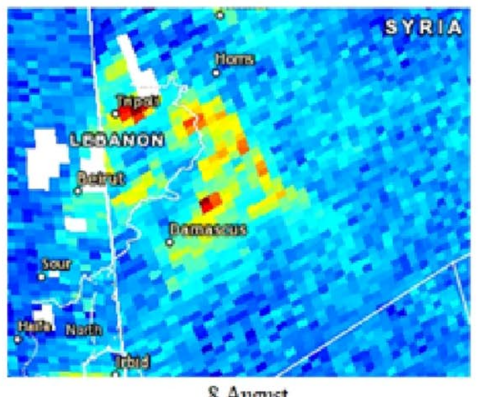

8 August

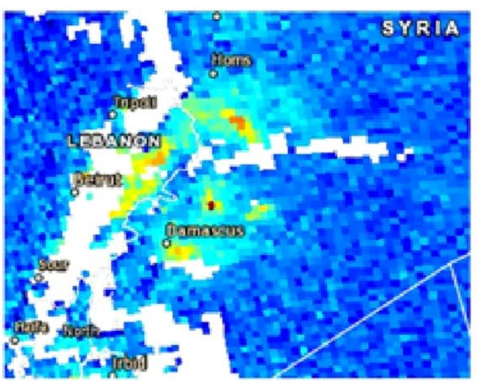

10 August

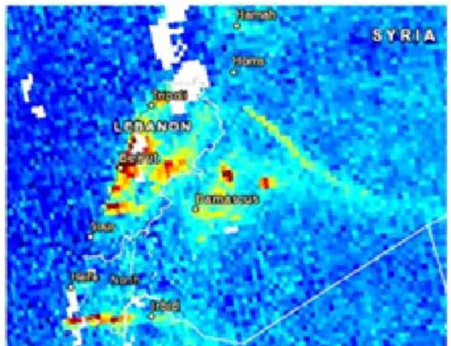

5 August

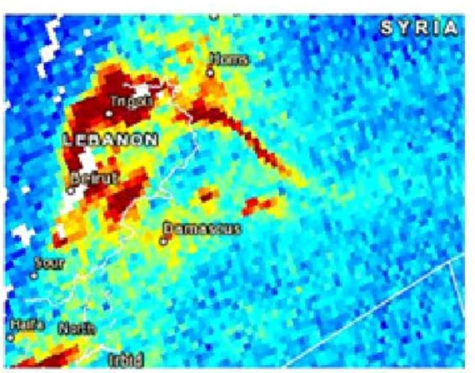

7 August

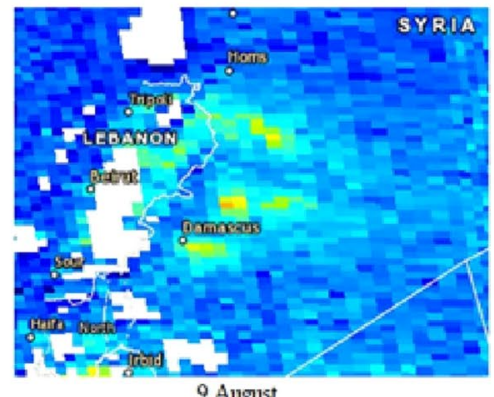

9 August

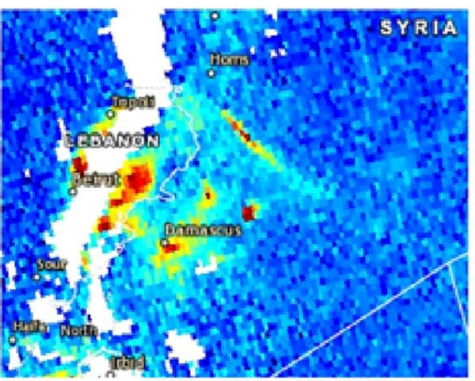

11 August 
Fig. 4 Vertical airflow at about $1500 \mathrm{~m}$ above sea level at Beirut, Lebanon, and the surrounding area ( $x$ axis: longitude, $y$ axis: latitude; omega values in the Beirut area were about +0.025 , which indicates downward airflow)

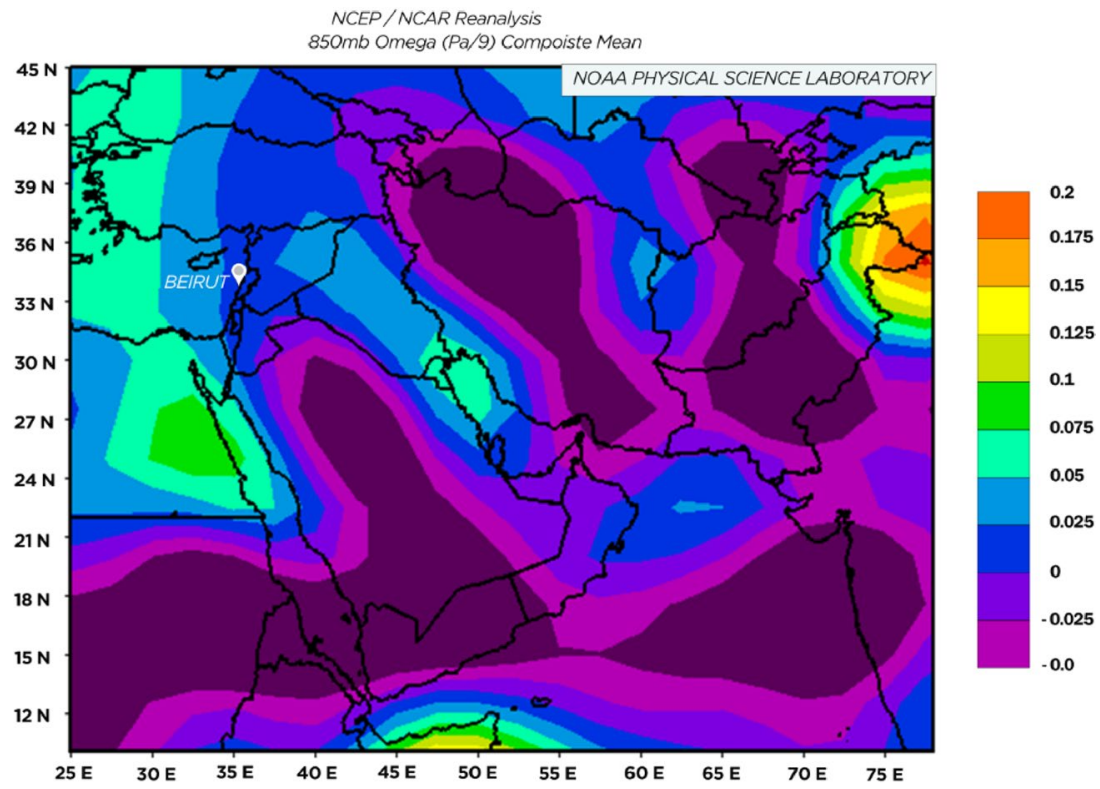

da Silva G (2020) What is ammonium nitrate, the chemical that exploded in Beirut? Sci Am 5 Aug 2020. Available online: https://www.scien tificamerican.com/article/what-is-ammonium-nitrate-the-chemicalthat-exploded-in-beirut/. Accessed 8 Aug 2020

Gan WQ, Davies HW, Koehoorn M, Brauer M (2012) Association of long-term exposure to community noise and traffic-related air pollution with coronary heart disease mortality. Am J Epidemiol 175(9):898

Meteoblue (2020) Meteoblue Weather Platform (MWP). Available online: www.meteoblue.com. Accessed 8 Aug 2020

NLM (United States National Library of Medicine) (2020) Nitrogen oxides. ToxTown: environmental health concerns and toxic chemicals where you live, work, and play. Available online: https://toxto wn.nlm.nih.gov/chemicals-and-contaminants/nitrogen-oxides. Accessed 9 Aug 2020

OCHA (United Nations Office for the Coordination of Humanitarian Affairs) (2020) Lebanon: Beirut Port explosions, situation report no. 1. Available online: https://reliefweb.int/sites/reliefweb.int/files/ resources/Beirut\%20Port\%20SitRep\%20No.\%201.pdf. Accessed 9 Aug 2020

Ogen Y (2020) Assessing nitrogen dioxide $\left(\mathrm{NO}_{2}\right)$ levels as a contributing factor to the coronavirus (COVID-19) fatality rate. Sci Total Environ 726:138605

PSL (NOAA Physical Science Laboratory) (2020) Real-time wind and vertical air movement data. Available online: https://psl.noaa.gov/ data/gridded/data.ncep. Accessed 9 Aug 2020

PurpleAir (2020) PurpleAir Air Quality Database. Available online: https://www.purpleair.com/map?opt=1/mAQI/a10/cC0\#10.25/33. 7453/35.4432.reanalysis.pressure.html. Accessed 8 Aug 2020

Shin S, Bai L, Oiamo T et al (2020) Association between road traffic noise and incidence of diabetes mellitus and hypertension in Toronto, Canada: a population-based cohort study. J Am Heart Assoc 9(6):e013021

Sinditskii V, Egorshev V, Levshenkov A, Serushkin V (2005) Ammonium nitrate: combustion mechanism and the role of additives. Propellants Explos Pyrotech 30(4):269-285

Sinergise Laboratory for Geographical Information Systems, Ltd. (2020) Sentinel Hub. Available online: https://apps.sentinel-hub.com/. Accessed 5-8 Aug 2020 
USEPA (United States Environmental Protection Agency) (2011) Air quality index. EPA-456/F-11-003. Office of Air and Radiation (6301A), Washington, DC

USEPA (United States Environmental Protection Agency) (2015) Chemical advisory: safe storage, handling, and management of solid ammonium nitrate prills. EPA 550-F-15-001. Occupational Safety and Health Administration, Washington, DC

Veefkind J, Aben I, McMullan K, Forster H, de Vries J, Otter G, Claas J, Eskes HJ, de Haan JF, Kleipool Q et al (2012) TROPOMI on the ESA Sentinel-5 precursor: a GMES mission for global observations of the atmospheric composition for climate, air quality and ozone layer applications. Remote Sens Environ 120:70
World Air Quality Index (2020) World Air Quality Index. Available online: https://aqicn.org/. Accessed 7 Aug 2020

WHO (World Health Organization) (2003) Health aspects of air pollution with particulate matter, ozone and nitrogen dioxide. EUR/03/5042688. Available online: https://www.euro.who.int/data/ assets/pdf_file/0005/112199/E79097.pdf. Accessed 31 Oct 2020

Publisher's Note Springer Nature remains neutral with regard to jurisdictional claims in published maps and institutional affiliations. 